\title{
Role of intranasal fluticasone furoate spray in modifying quality of life of children with adenoid hypertrophy
}

\author{
Md. Mazharul Islam ${ }^{1}$, AKM Rezaul Karim², Md.Ahsanul Habib ${ }^{3}$,Dr. Nafisa Zaman. ${ }^{5}$ Md.Tanvir Hasan ${ }^{4}$
}

\begin{abstract}
Introduction: Symptoms of adenoid hypertrophy is commonly seen among the pediatric age group. Since the surgical approach for this on immunity is controversial, the study was planned out to appraise the outcome of intranasal Fluticasone Furoate spray use.

Objective:To find out the efficacy of Fluticasone Furoate nasal spray in reducing clinical symptoms due to enlarged adenoid.
\end{abstract}

Methods: The prospective observational study was conducted in the Rangpur Medical College Hospital between April 2017 to August 2017 among 64 patients aged 4-15 years. Improvement on clinical symptoms was assessed by the structured OSA-18 questionnaire.

Results: At the end of 4 weeks, statistically significant improvement $(p<0.001)$ was observed in nearly all the domains of among the 64 participants. The average total score showed improvement from 60.95 to 46.37 .

Conclusion:The use of fluticasone furoate nasal spray considered to be useful in reducing clinical symptoms of adenoid hypertrophy among children.

Key words: Adenoid hypertrophy, Topical steroids, Fluticasone furoate,OSA-18Questionnaire.

1. Assistant Professor, Department of ENT, Rangpur Medical CollegeHospital.

2. Senior Consultant, Department of ENT, Rangpur Medical College Hospital.

3. Assistant Professor, Department of ENT, Rangpur Medical College Hospital.

5. Resident (MD course), Department of paediatrics.Rangpur Medical college Hospital.

4. Intern Doctor, Rangpur Medical College Hospital.

Address Of Correspondence:

Md. Mazharul Islam

Assistant Professor, Department of ENT, Rangpur Medical College, Rangpur

Introduction

The adenoid (PHARYNGEAL or Luschka's tonsil) forms part of Waldeyer's ring of lymphoid tissue at the portal of upper respiratory tract. In early childhood this is the first site of immunological contact for inhaled antigen ${ }^{1}$.In about six months to one year of life,the nasopharyngeal tonsil becomes evident; it gets larger in size during the first 6 to 8 years of life and generally shrinks by adolescence. Even though the etiology behind adenoid hypertrophy $(\mathrm{AH})$ is unclear, frequent infection, allergy, rhinitis and chronic sinusitis are commonly perceived as important causes ${ }^{2}$. Historically the adenoid has been associated with upper airway 
obstruction, as a focus of sepsis \& more recently with the persistence of otitis media with effusion (OME). An untreated $\mathrm{AH}$ may even lead to behavior alterations, low growth \& weight gain, craniofacial alterations secondary to mouth breathing, mastication and swallowing disorders, accompanied by corpulmonale and left heart failure ${ }^{3}$. Thus adenoidectomy is currently considered as the typical management strategy for children with severe symptoms caused by $\mathrm{AH}$, although some study suggests that more conservative treatments using topical, intranasally administered steroid preparations may have significant improvement ${ }^{4-7}$ in less serious cases. Herein the study is planned to see the clinical efficacy of Intranasal Spray(INS) Fluticasone Furoate in reducing enlarged adenoid in children.

\section{Methods}

The study was a prospective observational study. Sixty four patients (42 males, 22 females) ranging from 4 to 15 year old who visited the outpatient department of Otolaryngology Department with the complaints of snoring and nasal obstruction were selected between April 2017 to August 2017, with inclusion and exclusion criteria stated below, patients were selected and briefed about the study with written consent from the parents or legal guardians.

Inclusion criteria:

\section{Nasal obstruction, nasal discharge}

2. History of snoring for last 2 months or longer

3. Adenoid hypertrophy confirmed with simple $x-$ ray neck nasopharynx lateral view or endoscopic examination.

4. Patient with active URTI were treated with appropriate antibiotic and included in the study after 2 weeks of infection control.

\section{Exclusion criteria:}

1. URTI (Upper respiratory tract infection) within 2 weeks of entering the study.

2. Use of intranasal or systemic steroids within the last 6 months.

3. History of epistaxis, immunodeficiency disorders, or hypersensitivity to the Fluticasone furoate.

4. History of craniofacial, neuromuscular or genetic disorder.

OSA-18 questionnaire is used to validate the quality of life improvement. The OSA-18 is used as a valid and reliable tool for measuring quality of life (QOL) in children with varying levels of sleep disabled breathing ${ }^{8}$. At first the guardian was interviewed about the children and OSA-18 form filled up. Then the patients received fluticasone furoate 1 spray in each nostril once daily $(27.5 \mu \mathrm{g} /$ day $)$ for next 4 weeks, with followup and assessment of outcome by filing OSA-18 questionnaire again.

All the data gathered was presented as mean \pm standard deviation. Data was analyzed by appropriate parametric (Paired t-test) test. $(p<0.05)$ was considered as statistically significant improvement.

\section{Results}

Out of 1120 children attending the outpatient department of the tertiary hospital, 75 had adenoid hypertrophy, giving a prevalence of $6.69 \%$ (Figure 1). Among the 75 patients 64 completed the due course of treatment by INS fluticasone furoate over the 4 weeks regimen. 3 parents discontinued due to non-cooperation by the children, and 8 of them did not come for follow up. Among the 64, parents of 4 patients complained about dry mouth and slight epistaxis but had overcome the adversities without any medical aid. 5 patients aged 3-7 years had problems using INS due to sneezing and cough followed by the use of spray, but they ultimately completed the course. (Table 2) 
On table 3 before and after treatment survey of OSA-18 is shown. A significant improvement $(p<0.001)$ is seen as the average total score from 60.95 to 46.37 . All the parents informed that there was significant improvement in sleep pattern and physical symptoms which is evident by the scores 15.09 to 11.53 and 13.00 to 9.76 respectively. In all the domains of OSA-18 showed improvements of the course which is demonstrated by a bar chart, except in one domain that is discipline, which was not that significant. Following the INS spray treatment, frequent URI (upper respiratory infection) also improved markedly with the average score 3.54 to 2.61. Emotional distress reducing from 10.12 to 8.76 , overall parents' feedback was positive and appreciative for the non-surgical approach.

Table I: complications of fluticasone furoate nasal spray

\begin{tabular}{|l|c|}
\hline Features & Number \\
\hline No. of patients with complication & 14 \\
\hline Not well accepted by children & 3 \\
\hline Epistaxis & 4 \\
\hline Burning nose & 5 \\
\hline Dryness of nose & 2 \\
\hline
\end{tabular}

Bar Diagram showing mean score at OSA 18 score sheet before and after application of fluticasone spray.

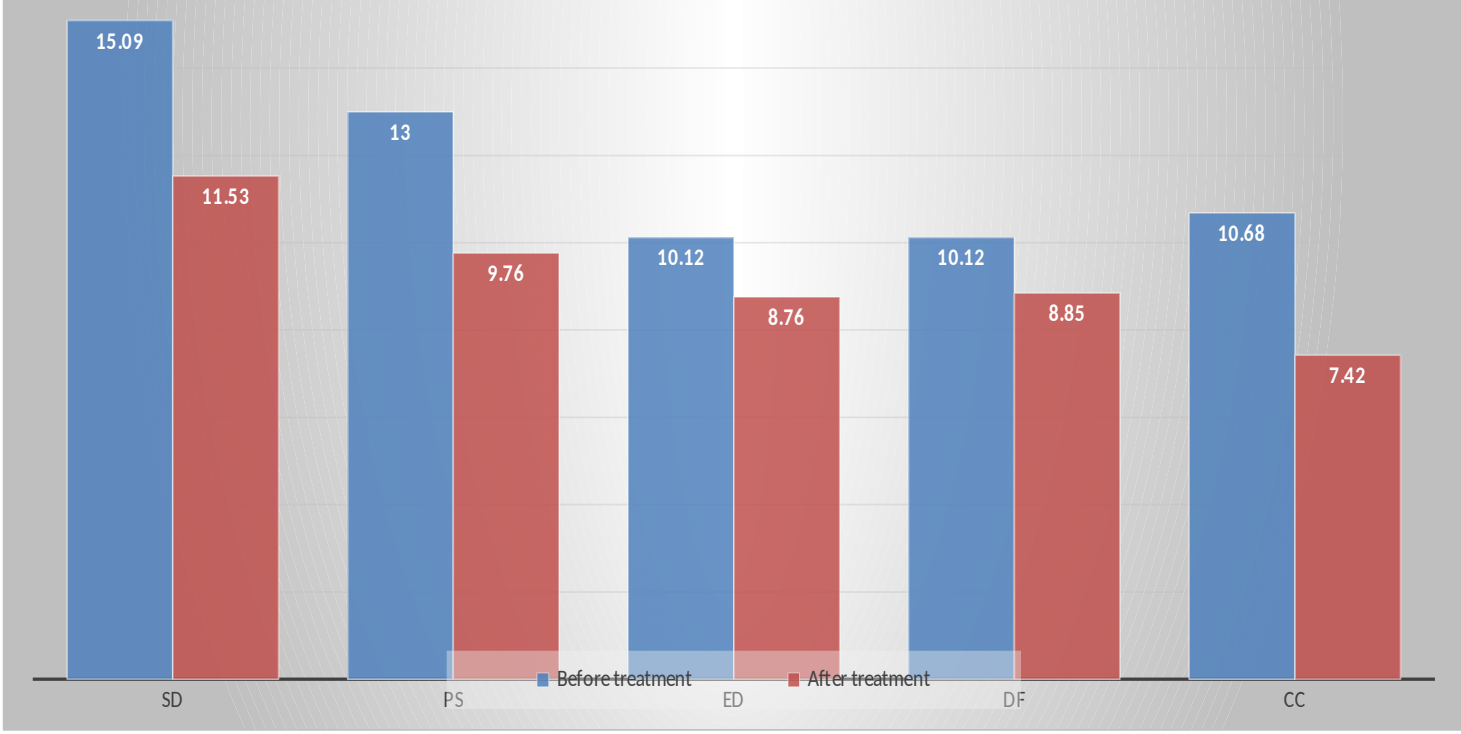

$(\mathrm{SD}=$ Sleep Disturbance, $\mathrm{PS}=$ Physical Symptom, ED= Emotional Disturbance, $\mathrm{DF}=$ Daytime Function, $\mathrm{CC}=$ Caregivers Concern). 
Table II: Parental questionnaire (OSA-18) results before and after intranasal fluticasone spray treatment

\begin{tabular}{|l|l|l|c|}
\hline & Before treatment & After treatment & P-value \\
\hline Sleep disturbance(SD) & $15.09 \pm 2.38$ & $11.53 \pm 2.34$ & $<0.001$ \\
\hline - Loud snoring & $4.03 \pm 1.15$ & $3.43 \pm 1.17$ & $<0.001$ \\
\hline - Breath holding/pause & $3.62 \pm 0.67$ & $2.78 \pm .90$ & $<0.001$ \\
\hline - Choking or gasping & $3.79 \pm 0.77$ & $2.54 \pm 0.86$ & $<0.001$ \\
\hline - Fragmented sleep & $3.64 \pm 0.62$ & $2.56 \pm 0.68$ & $<0.001$ \\
\hline & & & \\
\hline Physical symptoms(PS) & $13.00 \pm 3.28$ & $9.76 \pm 2.51$ & $<0.001$ \\
\hline - Mouth breathing & $3.73 \pm 1.12$ & $2.64 \pm 0.73$ & $<0.001$ \\
\hline - Frequent URI & $3.54 \pm 1.34$ & $2.61 \pm 1.26$ & $<0.001$ \\
\hline - Rhinorrhea & $2.85 \pm 0.82$ & $2.18 \pm 0.80$ & $<0.001$ \\
\hline - Dysphagia & $3.18 \pm 0.68$ & $2.83 \pm 0.50$ & $<0.001$ \\
\hline & & & \\
\hline Emotional distress(ED) & $10.12 \pm 1.25$ & $8.76 \pm 1.43$ & $<0.001$ \\
\hline - Mood swings or tantrums & $3.23 \pm 0.70$ & $2.76 \pm 0.67$ & $<0.001$ \\
\hline -Aggression/hyperactive & $3.20 \pm 0.68$ & $2.57 \pm 0.72$ & $<0.001$ \\
\hline - Discipline problems & $3.68 \pm 0.89$ & $3.42 \pm 0.80$ & 0.0846 \\
\hline & & & \\
\hline & & & \\
\hline Daytime functions & $10.8 \pm 1.09$ & $8.85 \pm 1.02$ & $<0.001$ \\
\hline - Daytime drowsiness & $3.78 \pm 0.94$ & $2.84 \pm 0.71$ & $<0.001$ \\
\hline - Poor attention span & $3.58 \pm 0.49$ & $2.87 \pm 0.51$ & $<0.001$ \\
\hline - Difficulty awaking & $3.48 \pm 0.55$ & $3.14 \pm 0.58$ & 0.009 \\
\hline & & & \\
\hline Caregiver concerns(CC) & $10.68 \pm 109$ & $7.42 \pm 1.56$ & $<0.001$ \\
\hline - Worried over child health & $3.71 \pm 1.51$ & $2.71 \pm 0.75$ & $<0.001$ \\
\hline - Concerned not enough air & $2.70 \pm 0.67$ & $2.04 \pm 0.62$ & $<0.001$ \\
\hline - Missed activities & $2.81 \pm 0.65$ & $1.76 \pm 0.98$ & $<0.001$ \\
\hline -Frustration & $2.34 \pm 1.24$ & $1.45 \pm 0.49$ & $<0.001$ \\
\hline & & & $<0.001$ \\
\hline Total & $60.95 \pm 6.25$ & $46.37 \pm 5.66$ & \\
\hline & & & \\
\hline & Data presented & 5901 & \\
\hline
\end{tabular}

(Data presented as mean \pm standard deviation; $p<0.05$ : Statistically significant using paired t' test)

\section{Discussion}

Adenoid Hypertrophy (AH) leads to different clinical manifestations according to adenoid size. Bilateral nasal obstruction being a primary complaint, a varying sleep disorders are often described, ranging from snoring to OSAS ${ }^{9}$. And so in the pediatric age group $\mathrm{AH}$ is considered as one of the most frequent pathologic condition. Being the secondary lymphoid organ, part of the mucosa-associated lymphoid tissue (MALT), adenoid presents immune activity mainly between 4 and 10 years of age $^{10}$. But in complications such as intermittent sleep, sleepwalking, morning headaches, difficulty concentrating, sleepiness, enuresis, slow feeding, and poor growth due to palatine tonsillar hypertrophy associated with $\mathrm{AH}$, patients are often suggested for surgery as the definitive treatment ${ }^{11}$. Even though adenotonsiliectomy is one of the commonest preferred procedure for childhood hypertrophy, Paulussen et al $^{12}$ hypothesized that the removal of adenoid lymphatic tissue could have a negative impact on the systemic immunologic system. Faramarzi et al $^{13}$ reported their concern over the true impact of adenotonsillectomy over 
pediatric immune system. Moreover, it is well demonstrated that adenoids may recur after surgery in $10 \%$ to $20 \%$ of cases ${ }^{14-15}$. Thus alternate non surgical approaches are well sought and topical nasal steroids were proposed by many authors from the past decade ${ }^{16-19}$. Chadha and Zhangs ${ }^{20}$ review on seven studies demonstrated significant efficacy of various nasal steroids in reducing adenoid size and in improving nasal obstruction symptoms, as measured with fiber-optic nasopharyngeal endoscopy and symptom scores, respectively.

In order to evaluate the alternative non-surgical treatment options, we used intranasal fluticasone furoate in children with adenoid hypertrophy as the data on Bangladeshi population is limited. The treatment was safe and well-tolerated with few minor adverse events. The OSA 18 questionnaire was used to evaluate the effects which are a standard protocol for quality of life evaluation.

The OSA-18 is an 18-item questionnaire that uses a Likert-type scoring system to collect information about 5 sub-scales that are considered to be elements in quality of life: sleep disturbance, physical symptoms, emotional symptoms, daytime function, and caregiver concerns. ${ }^{21}$ On the basis of this information, a summary score is calculated that ranges from 18 (no impact on quality of life) to 126 (major negative impact). A value at or above 60 is considered abnormal. ${ }^{22}$

The results were found to be in correspondence with the study done in India by Vipan Gupta et $\mathrm{al}^{23}$ with similar methodology with mometasone furoate. We chose Fluticasone furoate among many other commercially available steroid nasal sprays(beclomethasone propionate, budesonide, flunisolide, mometasone furoate, and triamcinolone acetonide) for mainly 4 reasons.(1) It is generally well tolerated, with types of side effects that are typical of INS class of medicine ${ }^{24}$, (2) It has no effects on the hypothalamic-pituitary-adrenal axis ${ }^{25}$, (3) the systemic availability of the drug after topical administration is lower than that of other steroids ${ }^{26}$ and (4) it has no effects on growth in children ${ }^{27}$.

The study of Brouillette et al $^{17}$ on 2001 on the efficacy of intranasal steroid treatment for OSAS in a randomized, triple-blind, placebo-controlled, parallel-group trial, investigating the use of fluticasone propionate nasal spray versus placebo for 25 children affected by OSAS revealed improvements in symptom scores in $69 \%$ of children. In another study of Hasan Demirhan et $\mathrm{al}^{28}$, after 8 weeks of treatment by Fluticasone propionate nasal drops,average total symptoms score dropped from 13.7 to 2.9. And this is well in accordance with our present study.

\section{Conclusions}

Treatment with nasal steroids can relief the symptoms of adenoidal hypertrophy and decrease the volume of adenoid. In this study, the effect of fluticasone furoate nasal spray on adenoid hypertrophy is evaluated for the first time. This method provides available alternative to surgical treatment in children with adenoid hypertrophy. But further long term treatment plan and observations (>1year) are essential to support the use of nasal steroids as a first-line approach in children.

\section{References}

1. PETER J ROBB., Scott-Brawn's Otorhinolaryngology, Head and Neck Surgery 7th edition vol.1 Chapter 84 The adenoid and adenoidectomy page 1095

2. Goetz. Pediatric Adenoidal Hypertrophy and Nasal Airway Obstruction: Reduction With Aqueous Nasal Beclomethasone. Pediatr. 1995;95(3):355 -364.

3. Kang K-T, Chou C-H, Weng W-C, Lee P-L, Hsu W-C. Associations between Adenotonsillar Hypertrophy, age and obesity in children with obstructive sleep apnea. PLoS ONE. 2013;8(10):78666. 
4. Demain JG, Goetz DW. Pediatric adenoidal hypertrophy and nasal airway obstruction: reduction with aqueous nasal beclomethasone. Pediatrics. 1995;95:355-364

5. Brouillette RT, Manoukian JJ, Ducharme FM, et al. Efficacy of fluticasone nasal spray for pediatric obstructive sleep apnea. J Pediatr. 2001;138:838-844

6. Criscuoli G, D'Amora S, Ripa G, et al. Frequency of surgery among children who have adenotonsillar hypertrophy and improve after treatment with nasal beclomethasone. Pediatrics. 2003;111:236-238

7. Cengel S, Akyol MU. The role of topical nasal steroids in the treatmentofchildrenwithotitismediawi theffusionand/oradenoid

hypertrophy. Int J PediatrOtorhinolaryngol. 2006;70:639-645

8. Silva VC, Leite AJ. Quality of life in children with sleep-disordered breathing: evaluation by OSA-18. Braz Otorhinolaryngol2006;72:747-756

9. Craig TJ, Teets S, Lehman EB, Chinchilli VM, Zwillich C. Nasal congestion secondary to allergic rhinitis as a cause of sleep disturbance and daytime fatigue and the response to topical nasal corticosteroids. J Allergy ClinImmunol. 1998;101:633-637

10. Nave H, Gebert A, Pabst R. Morphology and immunology of thehuman palatine tonsil. AnatEmbryol (Berl) 2001;204:367373

11. Mira JGS, Pasinato RC, Mocellin M, Ferreira Neto O, CapassoR, Catam GSA, et al. Efeitos da adenoamigdalectomianosistemaimu nehumoral. Rev Bras

Otorhinolaryngol 1998;64:437-440.

12. Paulussen C, Claes J, Claes G, Jorissen M. Adenoids and tonsils, indications for surgery and immunological consequences of surgery. ActaOtorhinolaryngol Belg. 2000;54:403-408

13. Faramarzi A, Shamseddin A, Ghaderi A. IgM, IgG serum levelsand lymphocytes count before and after adenotonsillectomy. IranJImmunol 2006;3:187-191.

14. Kovaleva LM. Repeated adenoidectomy and prevention of the recurrence of adenoid hypertrophy [in Russian]. VestnOtorinolaryngol. 1994;1:18-21

15. Buchinsky FJ, Lawry MA, Isaacson G. Do adenoids regrow after excision? Otolaryngol Head Neck Surg. 2000;123:576-581

16. Demain JG, Goetz DW. Pediatric adenoidal hypertrophy and nasal airway obstruction: reduction with aqueous nasal beclomethasone. Pediatrics. 1995;95:355-364

17. Brouillette RT, Manoukian JJ, Ducharme FM, et al. Efficacy of fluticasone nasal spray for pediatric obstructive sleep apnea. J Pediatr. 2001;138:838-844

18. Criscuoli G, D'Amora S, Ripa G, et al. Frequency of surgery among children who have adenotonsillar hypertrophy and improve after treatment with nasal beclomethasone. Pediatrics. 2003;111:236-238

19. Cengel S, Akyol MU. The role of topical nasal steroids in the treatmentofchildrenwithotitismediawi theffusionand/oradenoid. Int $\mathrm{J}$ hypertrophy PediatrOtorhinolaryngol. 2006;70:639-645 
20. Chadha NK, Zhang L, MendozaSassi RA, César JA. Using nasalsteroids to treat nasal obstruction caused by adenoid hypertrophy: does it work? Otolryngol Head Neck Surg 2009;140:139-147.

21. Chervin RD, Hedger K, Dillon JE, Pituch KJ. Pediatric Sleep Questionnaire (PSQ): va-lidity and reliability of scales for sleepdisordered breathing, snoring, sleepiness,and behavioral problems.SleepMed.2000;1(1):2132.

22. Franco RA Jr, Rosenfeld RM, Rao M. Firstplace: resident clinical science award 1999.Quality of life for children with obstructivesleep apnea. Otolaryngol Head Neck Surg.2000;123(1 pt 1):9-16.

23. Vipan Gupta, Monika Gupta, prithipal S Matreza, et al. Efficacy of Mometasone Nasal Spray in Children with Snoring due to Adenoids. 10.5005/jp-journals10013-1179.

24. J.H. van Bavel, Toler T, Ellsworth A et al. Once-daily fluticasone furoate* nasal spray (FFNS) improved quality of life(QoL) in subjects with seasonal allergic rhinitis (SAR) during the mountain cedar pollen season. *USAN approved name. J Allergy Clinlmmunol 2007; 119(Suppl1):S231

25. Boner AL. Effects of intranasal corticosteroids on the hypothalamicpituitary-adrenal axis in children. $\mathrm{J}$ Allergy 2001;108(suppl):S32-S39

26. Szefler SJ. Pharmacokinetics of intranasal corticosteroids. J Allergy Clinlmmunol. 2001;108(suppl):S26S31

27. Stefanovic, I. M., Verona, E., Cicak, B. and Vrsalovic, R. (2011), No effect of fluticasone propionate on linear growth in preschool children with asthma. Pediatrics international. 2011;53:672-676.

28. Demirhan H, Aksoy F, Ozturan O, Yildirim YS, VeysellerB.medical treatment of adenoid hypertrophy with "fluticasone proprionate nasal drops". Int J Pediatr Otorhinolaryngol.2010 Jul;74(7):773-6. 